\title{
Evaluation of the Urban Low-Carbon Sustainable Development Capability Based on the TOPSIS-BP Neural Network and Grey Relational Analysis
}

\author{
Wei Zhang, ${ }^{1}$ Xinxin Zhang, ${ }^{1}$ Fan Liu $\mathbb{D}^{,},{ }^{2}$ Yan Huang, ${ }^{2}$ and Yuwei Xie ${ }^{2}$ \\ ${ }^{1}$ School of Public Administration, Central China Normal University, Wuhan 430079, China \\ ${ }^{2}$ School of Business Administration, Zhongnan University of Economics and Law, Wuhan 430073, China \\ Correspondence should be addressed to Fan Liu; liufan_zuel@163.com
}

Received 1 November 2020; Revised 18 November 2020; Accepted 10 December 2020; Published 22 December 2020

Academic Editor: Baogui Xin

Copyright (c) 2020 Wei Zhang et al. This is an open access article distributed under the Creative Commons Attribution License, which permits unrestricted use, distribution, and reproduction in any medium, provided the original work is properly cited.

With the development of industrialization and urbanization, cities have become the main carriers of economic activities. However, the long-term development of cities has also caused damage to resources and the environment. Hence, objective and scientific evaluation of urban low-carbon sustainable development capacity is very important. An index system of urban lowcarbon sustainable development capability is constructed in this paper, and a TOPSIS-BP neural network model is established to evaluate the low-carbon sustainable development capability of Beijing, Shanghai, Shenzhen, and Guangzhou in China. At the same time, the difference degree of low-carbon sustainable development level in these four cities is analyzed by standard deviation and coefficient of variation, and the influencing factors of urban low-carbon sustainable development ability are extracted by grey correlation analysis. The results show that (1) the capability of low-carbon sustainable development in four cities is rising and the difference of low-carbon sustainable development capability is decreasing; (2) the general view that the higher the general investment in low-carbon sustainable development, the higher the level of low-carbon sustainable development in cities has not been verified; (3) with the change of time series, the factors affecting the capability of low-carbon sustainable development in the same city are different and the influence of the same factor on the capability of low-carbon sustainable development in different cities is different.

\section{Introduction}

Green development emphasizes the coordination and mutual benefit of economic development, resource utilization, and ecological environment. Campbell [1] used a triangle model to study the priority of urban development planning. He believes that urban and rural development must take sustainable development as a vision and coordinate the conflicts between economic, environmental, and social interests. At present, green development has become an important trend in social and economic development. As the main carrier of economic activities, cities play an important role in the process of promoting economic development. According to the report of the National Bureau of Statistics, from 2010 to 2019, China's urbanization rate increased from $49.95 \%$ to $60.6 \%$, an average annual increase of $1.065 \%$. The rapid development of urbanization has brought a lot of employment opportunities and promoted the rapid development of real estate, infrastructure construction, and other related industries. This has greatly promoted the growth of GDP. According to a survey conducted by the National Bureau of Statistics, in 2019, China's top 100 cities have 13\% of the country's land and $50 \%$ of the population, creating about $73 \%$ of GDP, accounting for about $62 \%$ of the country's commercial housing sales. However, the rapid development of cities has also brought about a large amount of energy consumption and energy and carbon dioxide emissions, and the contradiction between economic development and resources and the environment has become more and more intense [2]. Discharge of industrial waste and waste of water resources has brought severe challenges to the sustainable development of urban economic 
environment. In 2019, the average PM2.5 concentration of 337 prefecture-level and above cities across the country was $36 \mathrm{micrograms} / \mathrm{m}^{3}$, and cities with up to standard ambient air quality accounted for only $46.6 \%$ of all cities. Under the new economic normal, how to achieve energy conservation and emission reduction, enhance the sustainability of resource utilization, and reduce environmental pressure in urban development has become an important challenge for urban green development.

Therefore, there are more and more researches on urban green sustainable development. In terms of research content, part of the research focuses on the planning of urban green spaces. Van Herzele and Wiedemann [3] believed that urban green space has largely affected the quality of urban life. Therefore, they proposed a comprehensive index and used GIS technology to study the use of urban green space [4]; Horwood [5] uses the green infrastructure (GI) method to study the construction of urban green spaces and points out that the way of economic development affects the construction of urban green spaces. In addition, some studies mainly focus on the urban ecological environment [5-7]. Thorén [8] emphasized the importance of the environment and established an indicator system to evaluate the sustainability of the urban green structure. Brundtland et al. [9] believe that the sustainable development of the urban environment needs to meet the economic and social welfare conditions to improve the quality of the residents' living environment. Some scholars study the green development of cities from the aspects of technological innovation and technology $[10,11]$. By designing an index system, evaluating the degree of green development of a city has also become an aspect of research [12]. In terms of research methods, Zhao et al. [13] is based on analytic hierarchy process (AHP) and uses data cluster analysis to study China's regional innovation and development capabilities; $\mathrm{Li}$ and Lin [14] used the DEA model to analyze the green growth rate of China's manufacturing industry; Duan et al. [15] based on the AHP-entropy method established an index system to evaluate the development level of Dalian's lowcarbon economy. The main focus of the abovementioned literature is the sustainable development of the urban ecological environment. It pays less attention to the sustainable development of the urban economy, and the research method is relatively simple. In the case of more data, the amount of calculation is large and error-prone. However, in the new economic situation, the coordinated promotion of high-quality economic development and ecological environmental protection is the key to improving urban green development capabilities. In addition, the evaluation of urban green development capabilities also requires more complete evaluation methods to be able to more objectively evaluate urban green development capabilities and analyze the factors that affect the level of urban green development.

Beijing, Shanghai, Shenzhen, and Guangzhou are the four most economically powerful cities in mainland China. They are all national central cities and are also known as the "first-tier cities" of China's three major gateways. Among them, Beijing is the political center of China. As of the end of 2019, Beijing's urbanization rate reached $86.6 \%$. "2016 China
Urban Sustainability Report: Measuring Ecological Investment and Human Development" pointed out that Beijing's Human Development Index ranked second among Chinese cities. Shanghai is located in the Yangtze River Delta, in the east of China, at the mouth of the Yangtze River. In 2014, Shanghai's GDP ranked first among Chinese cities and second in Asia. In 2019, the "Top 100 Chinese Cities Green Competitiveness Ranking" was released, and Shanghai ranked 10th. Shenzhen is the window of China's reform and opening up. In the 2012 "World's Most Economically Competitive Cities" list by the Economist, Shenzhen ranked second; in 2019, it ranked third in the China City Creative Index. Guangzhou is an important central city and international trade center in China. Guangzhou has more than 8,700 national high-tech enterprises, ranking top three in the country in total. The four cities of Beijing, Shanghai, Shenzhen, and Guangzhou are relatively at the leading level in terms of comprehensive strength and competitiveness among the cities in mainland China, with a strong economic foundation and strong scientific research capabilities. Therefore, compared with other cities in China, the four cities of Beijing, Shanghai, Shenzhen, and Guangzhou have relatively high urban green development capabilities and levels. Assess the green development level of these four cities and evaluate the factors affecting the urban green development level. The analysis can serve as a model and reference for the green development of other cities in China.

This paper takes Beijing, Shanghai, Shenzhen, and Guangzhou as the research objects and designs an index system for evaluating the level of urban green development. Based on the entropy TOPSIS-BP neural network model, the green development levels of Beijing, Shanghai, Shenzhen, and Guangzhou are evaluated. At the same time, this paper uses the gray correlation analysis method to analyze the factors that affect the level of urban green development and provides references for the green development of other cities.

\section{Literature Review}

2.1. Research on the Content of Urban Green Development. The green development and sustainable development of a city are in the same line [16]; early research on urban green development focused on environmental sustainability [17]. Therefore, some scholars have done a lot of research on urban green space and ecological environment. For example, Haq [18] conducted empirical research on different cities and proposed to maintain urban green space to develop sustainable cities that improve the environment; Budruk et al. [19] investigates the use of green space in Indian cities and analyzes the importance of urban green space to sustainable urban green development; Wolch et al. [20] compares the development of green cities in the United States and China and supports sustainable urban green development strategies to protect the urban ecology; Dou et al. [21] emphasized the important role of urban ecological environment in urban green development and believed that implementing an ecological ecological city development strategy is the most effective way to achieve sustainable 
urban development; Wu et al. [22] reviewed the research on urbanization and urban ecology in China and believed that the sustained and rapid development of Chinese cities requires the establishment of a scientific urban ecosystem; Niemelä et al. [23, 24] believe that the ecological service system is essential to urban life, and the green and sustainable development of cities requires reasonable planning of land resources, increasing vegetation coverage, and maintaining biodiversity.

With the development of the economy and society and the in-depth understanding of the concept of sustainable development, the research content of urban green development is no longer limited to the sustainable ecological environment and should be coordinated with environmental protection in the process of economic development [25]. Rees [26] believes that the study of urban economics has neglected the urban ecological environment and pointed out that it is necessary to formulate sustainable development strategies for the urban economy based on changes in the ecological environment; Campbell [1] believes that researchers should take sustainable urban development as the main goal. At the same time, it is combined with technology to solve the problem of incoordination between economic development and ecological environment; Dempsey et al. [27] believe that the green development of cities should not only consider the ecological environment but also the sustainable development of the urban economy; Rees et al. $[26,27]$ took British urban development as the research object, incorporated economic and social aspects into the content of sustainable urban development, and discussed the relationship between urban form and social sustainability. With the rapid development of urbanization and rapid changes in the ecological environment, it is increasingly important to explore the synergistic relationship between urban politics, economy, and ecological environment [28]. Urban green building development also plays an important role in urban green development [29]. The development of urban green space systems can effectively respond to the challenges of urbanization, such as protecting biodiversity and adapting to climate change $[30,31]$. Therefore, Barles [32] reviews the process of urban development and believes that while the city consumes energy and resources in the development process; it must take into account the impact on the ecological environment. This is an unavoidable problem for the green development and sustainable development of cities.

The green development of the city mainly emphasizes the coordinated development of economy, ecology and society, and optimization of resource utilization. It can be seen from the abovementioned literature research that the research direction and focus of different scholars are different. These studies all involve the green development of cities, such as the planning and management of urban green space, the utilization of urban land resources, and the importance of the sustainable development of the urban ecological environment. However, the above literature mainly emphasizes the importance of urban sustainable development from a macroperspective, and there is little analysis of the factors that realize urban green development. Because urban development needs to take up a lot of natural resources and other resources, it is also necessary to achieve coordinated development with the economy, environment, and society and maximize the benefits of urban development. Therefore, there are still many problems to be solved on how to improve the city's green development ability and level.

\subsection{Research on the Evaluation of Urban Green Development.} With the rapid development of urbanization, there are more and more researches on urban green development. How to evaluate the ability and level of urban green development has also become the research focus of scholars. In terms of evaluation content, Chen and Wang [33] used panel data of 285 Chinese cities to conduct quantitative analysis to evaluate urban green spaces. This allows decision-makers to better weigh the relationship between economic development and natural facilities. Jin et al. [11] use the two influencing factors of macroeconomics and high-level innovation ability to evaluate the performance of urban green development. Li et al. [34] designed and developed 52 indicators based on Jining, Shandong, China. These indicators are economic growth and economic efficiency, ecological environment protection, and urban infrastructure construction. And, they developed a comprehensive index method of completely replacing polygons to evaluate the sustainable development ability of the city. Zhang et al. [10] used 103 cities in China as research objects, selected two indicators of knowledge innovation and product innovation, and used a spatial autoregressive model to verify the impact of innovation on the level of urban green development. Guan et al. [35] took Chongqing, China, as an example, combined system dynamics (SD) and geographic information system (GIS), and proposed a dynamic combination method of SD-GIS. The sustainable development level of Chongqing through modeling is evaluated. In terms of evaluation methods, Thinh et al. [36] created an ARC/ INFO database of land use patterns. And through modeling, a cluster analysis of 116 cities in Germany was carried out to find ways to promote the sustainable development of cities. Thinh et al. [36, 37] used an improved entropy method combining experts and entropy weights to propose an indicator system for the evaluation of urban circular economy development. And put forward suggestions to promote the development of urban circular economy. Ding et al. [38] constructed an indicator system from three aspects: society, economy, and environment. The TOPSISentropy method is used to evaluate the sustainable development level of 287 prefecture-level and above cities in China, and the spatial distribution of the urban sustainable development level is analyzed. Meng et al. [39] used panel data of 31 provinces in China as the object to establish an indicator system and used the catastrophe progression method to measure the level of green economy development in 31 provinces in China. Lin and Ying [40] used the DEA model to evaluate the green development efficiency of urban agglomerations in the Middle Delta and the Yangtze River Delta and compared their green development efficiency. Zheng et al. [41] measured the green development 
level of 78 cities in China from the perspective of urban household carbon emissions.

From the above evaluation research on urban green development, it can be found that most scholars use the method of establishing an index system to evaluate the level of urban green development. However, most of these indicators focus on urban green space planning and ecological environment, while there are few studies that take into account economic development, ecological environment, and social development. And, it is lack of attention to scientific research and innovation. In improving the ability of urban green development, the innovation of green technology plays an important role in sustainable economic growth and alleviating environmental pressure. In addition, most of the existing studies use AHP, entropy method, and TOPSIS to determine indicator weights and calculate the comprehensive level of urban green development. These research methods are subjective. Kahn [42] believes that selecting multiple indicators and adding weights through objective methods can solve subjective problems to a certain extent. This article summarizes the research of existing scholars and adds the indicator of green innovation technology. This article adopts the TOPSIS-BP neural network method to evaluate the green development review of the four cities of Beijing, Shanghai, Shenzhen, and Guangzhou, which is more objective. In addition, this paper also uses methods such as grey correlation analysis to extract the factors that affect the green development of cities, analyze which are the important factors, and provide certain references for the green development of other cities.

\section{Research Design}

3.1. Model Construction. The entropy TOPSIS method can eliminate subjective errors and relatively objectively measure the weight of each evaluation index and the level of green development of the city. The BP neural network can learn the standards. After training, it can stably simulate the evaluation of experts, determine the weight of each index, reduce the influence of subjective factors in different situations, and also get the green development level of each city. And, the BP neural network can verify the results obtained by the entropy TOPSIS method, so as to more truly reflect the level of urban green development.

However, the entropy TOPSIS method and BP neural network can measure the green development level of different cities. However, different cities have differences in resource endowments, resource allocation, location conditions, and external environment, which will cause differences in the level of green development and influencing factors between cities. Therefore, it is necessary to use the standard deviation and the coefficient of variation to quantitatively measure the degree of difference and use the grey correlation analysis to identify the factors that cause the difference.

3.1.1. Entropy Weight TOPSIS Method. The entropy method is an objective weight determination method that can be used to measure the weight of known data [43]. Rubinstein [44] proposes an entropy weight evaluation method is to determine the index weight, which is used to evaluate the water quality of the Three Gorges Reservoir. Zhao et al. [45] also use the entropy method to determine the index weight to assess environmental vulnerability; Sun et al. [46] use the entropy TOPSIS evaluation model to evaluate the impact of green technological innovation on the ecological economic efficiency of strategic emerging industries. In order to truly reflect the green development capabilities of China's firsttier cities, this article uses a relatively objective entropy method to determine the weight of each indicator. The specific steps are as follows.

Firstly, the raw data has to be standardized. The indicators that measure the green development capabilities of the first-tier cities in China have differences in dimensions and orientations. In order to avoid the influence between data, all indicators should be normalized according to the orientation of the data. Since different indicators have different impacts on urban green development, the indicators $y_{i j}$ can be divided into positive indicators $y_{i j}^{+}$and negative indicators $y_{i j}^{-}$. The formulas are as follows:

Positive indicators:

$$
y_{i j}^{+}=\frac{x_{i j}-\min \left\{x_{1 j}, x_{2 j}, \ldots, x_{n j}\right\}}{\max \left\{x_{1 j}, x_{2 j}, \ldots, x_{n j}\right\}-\min \left\{x_{1 j}, x_{2 j}, \ldots, x_{n j}\right\}} .
$$

Negative indicators:

$$
y_{i j}^{-}=\frac{\max \left\{x_{1 j}, x_{2 j}, \ldots, x_{n j}\right\}-x_{i j}}{\max \left\{x_{1 j}, x_{2 j}, \ldots, x_{n j}\right\}-\min \left\{x_{1 j}, x_{2 j}, \ldots, x_{n j}\right\}},
$$

$x_{i j}$ is the jth index of $i$ area, $\min \left(x_{i j}\right)$ is the minimum value of the sample data, and $\max \left(x_{i j}\right)$ is the maximum value of the sample data.

Secondly, the entropy $H_{j}$ is calculated. The formula is

$$
H_{j}=-k \sum f_{i j} \times \ln f_{i j},
$$

where $k=(\ln m)^{-1}$ and $f_{i j}$ is the the normalized value of $y_{i j}$. Because the scope of $y_{i j}$ is $[0,1)$, we normalized $y_{i j}$ by formula (4) to guarantee that $\ln f_{i j}$ is meaningful:

$$
f_{i j}=\frac{1+y_{i j}}{\sum_{i=1}^{m}\left(1+y_{i j}\right)} .
$$

Finally, calculate the weights:

$$
W_{j}=\frac{1-H_{j}}{\left(n-\sum_{j=1}^{m} H_{j}\right)} \text {. }
$$

Then, it is combined with the weighted Topsis method to calculate the green development capacity of the first-tier 
cities in mainland China from 2009 to 2018. Weighted Topsis is also known as the distance method of superior and inferior solution. Since it can make full use of the original data to reflect the superiority and inferiority of each evaluation plan, it is used to calculate the green development capabilities of Beijing, Shanghai, Shenzhen, and Guangzhou. Rashidi and Cullinane [47] applying the Topsis method to sustainable supplier evaluation, it is found that TOPSIS is superior to DEA in terms of computational complexity and sensitivity to changes in the number of suppliers. Dos Santos et al. [48] use TOPSIS to determine environmental standards for evaluating and selecting green suppliers in the furniture industry; In [49], combined with TOPSIS, the influence of multiattribute decision-making on the efficiency of the reverse logistics industry of scrapped automobiles is analyzed to improve the efficiency of resource utilization.

Specific steps are as follows:

Firstly, weigh the preprocessed data. Multiply the preprocessed data with the corresponding index weight to obtain a weighted normalized decision matrix:

$$
A=a_{i j}=\left(Z_{i j} \times W_{j}\right)
$$

Secondly, build positive ideal solution vectors separately $a_{j}^{+}$and negative ideal solution vector $a_{j}^{-}$:

$$
\begin{aligned}
& a_{j}^{+}=\max \left(a_{1 j}, a_{2 j}, a_{3 j}, \ldots, a_{m j}\right), \\
& a_{j}^{-}=\min \left(a_{1 j}, a_{2 j}, a_{3 j}, \ldots, a_{m j}\right) .
\end{aligned}
$$

Thirdly, calculate the optimal distance and the worst distance. The Euclidean calculation formula is used to calculate the optimal distance from the evaluation value vector to the positive ideal solution and the worst distance to the negative ideal solution. The optimal and worst distance calculation formulas are, respectively,

$$
\begin{aligned}
& d_{j}^{+}=\sqrt{\sum_{j=1}^{n}\left(a_{i j}-a_{j}^{+}\right)^{2}}, \\
& d_{j}^{-}=\sqrt{\sum_{j=1}^{n}\left(a_{i j}-a_{j}^{-}\right)^{2}} .
\end{aligned}
$$

Finally, calculate the closeness of each evaluation object. The closeness indicates how close each evaluation object is to the optimal distance. The larger the value, the closer the evaluation object is to the optimal level.

The calculation formula is

$$
B_{i}=\frac{d_{i}^{-}}{d_{i}^{-}+d_{i}^{+}}, \quad 0 \leq B_{i} \leq 1 .
$$

3.1.2. Neural Network Model Construction. BP neural network is a multilayer feedforward neural network trained according to the error back propagation algorithm, which can make important contributions to the development of faster learning algorithms and research [50]. The neuron is the basic unit of the neural network. For the $i$ th neuron, $X_{1}$, $X_{2}, \ldots, X_{j}$ are the inputs of the neuron, and the input is often the independent variable that has a key impact on the system model, and $W_{1}, W_{2}, \ldots, W_{j}$ are the connections the weight adjusts the proportion of each input. Structurally, the BP network has an input layer, a hidden layer, and an output layer; in essence, the BP algorithm uses the square of the network error as the objective function and uses the gradient descent method to calculate the minimum value of the objective function. Therefore, using BP neural network to predict and evaluate is more objective and scientific. Peng and Lai [51] use neural network model to evaluate the effectiveness of tourism e-commerce service innovation. $\mathrm{Li}$ and Wang [52] use the BP correction model to predict India's dependence on foreign oil. Zhang et al. [53] based on the BP neural network established an evaluation model to evaluate the smart growth plan of the city.

The calculation process of the BP neural network model is as follows:

(1) The model is build with full connected layers:

$$
\alpha_{j}=\sum_{i=1}^{d} w_{i j} * x_{i},
$$

$w_{i j}$ is the weight and $x_{i}$ is the input of each layer.

(2) The activation function is

$$
b_{j}=f\left(\alpha_{j}-\gamma_{j}\right) .
$$

(3) Calculate the error:

$$
E_{k}=\frac{1}{2} \sum_{h=1}^{l}\left(y_{h}^{k}-y_{h}^{k}\right)^{2} .
$$

(4) Update each weight with the chain rule:

$$
w_{j h}^{\prime}=w_{j h}-\eta * \frac{\partial E}{\partial w_{j h}} .
$$

(5) Repeat execution to minimize the cost function value.

\subsection{Analysis Method of Urban Green Development}

3.2.1. Standard Deviation and Variation Coefficient. This paper used standard deviation and variation to analyze the difference characteristics of urban green development capabilities. The larger the standard deviation and the coefficient of variation, the greater the difference in green development capabilities between cities. Bobinaite et al. [54] combined the standard deviation and the coefficient of variation to analyze the price characteristics (volatility and 
peak value) of the Lithuanian and Polish day-a-day power market in order to better understand the process of price formation in the Polish and Lithuanian power market, so as to provide a theoretical basis for the country to implement national energy policies and measures. The calculation formulas for standard deviation and coefficient of variation are

$$
\delta^{2}=\left[\frac{1}{n} \sum_{1}^{n}\left(X_{i j}-\frac{1}{n} \sum_{1}^{n} X_{i j}\right)\right]^{1 / 2},
$$

where $\delta^{2}$ indicates the standard deviation of the city's green development capability during the study period, $(1 / n) \sum_{1}^{n} X_{i j}$ is the average level of green development capacity of $n$ cities in the $i$ th year, and $n$ is the number of cities, where $X_{i j}$ is the green development capacity of the $j$ city in the $i$ year.

Record the mean value $M=(1 / n) \sum_{1}^{n} X_{i j}$, which represents the average green development capacity of $n$ cities in the $i$ year. The coefficient of variation $(C \cdot V)$ is the ratio of the standard deviation to the mean. The larger the value, the larger the green development capacity gap between cities.

3.2.2. Grey Relational Analysis. The development of the system is often affected by many factors, and the influence of each factor on the system is different. Grey relational analysis has no requirements on the size and regularity of the sample and can judge whether the connection is close according to the similarity of the geometric shape of the sequence curve. The closer the curve is, the greater the correlation between the corresponding sequences, and vice versa. Related scholars have also applied the gray relational analysis method to practical research. The grey correlation analysis method is used to determine the factors that have a strong correlation with carbon emissions, which provides a theoretical basis for reducing carbon emissions [55]. Sun and Tang [56] taking 12 cities in Hunan Province as the empirical analysis object and using the gray correlation analysis method, it is found that the correlation between scientific and technical personnel and economic development is greater than the correlation between scientific and technological expenditure and economic development. Therefore, the grey correlation analysis method is used to extract the factors that affect the city's green development ability.

Specific steps are as follows:

(1) Determine the comparison sequence and the reference sequence. Take the index to measure the green development capacity of the first-tier cities in China as the comparison sequence $X_{1}(k)$, taking the green development capabilities of Beijing, Shanghai, Shenzhen, and Guangzhou from 2009 to 2018 as a reference sequence $X_{0}(k)$.

(2) Preprocess the comparison sequence and the reference sequence. The formula is

$$
\begin{aligned}
X_{i}^{\prime}(k) & =\frac{X_{i j}}{(1 / n) \sum_{i}^{n} X_{i j}}, \\
X_{0}^{\prime}(k) & =\frac{X_{0}(k)}{(1 / n) \sum_{i}^{n} X_{0}(k)} .
\end{aligned}
$$

Get a new comparison sequence $X_{i}^{\prime}(k)$ with reference sequence $X_{0}^{\prime}(k)$.

(3) Calculate the grey correlation coefficient. Find the absolute difference between the preprocessed comparison sequence and the reference sequence $\Delta_{0 i}(k)$; among them, $\Delta_{0 i}(k)=\left|X_{i}^{\prime}(k)-X_{0}^{\prime}(k)\right|$. And, get the maximum difference $M$ and the minimum difference $m$. According to the formula,

$$
\delta_{0 i}(k)=\frac{m+\rho M}{\Delta_{0 i}(k)+\rho m} .
$$

The grey correlation coefficient is calculated, $\rho$ is the resolution coefficient, and 0.5 is better.

(4) Calculate the correlation coefficient of each indicator to the overall system $r\left(X_{0}, X_{i}\right)$, where $\left(X_{0}, X_{i}\right)=\left(\sum_{k=1}^{n} \delta_{0 i}(k) / n\right)$. At this time, the correlation degree between each element in the indicator and the corresponding element in the parent sequence can be obtained. The higher the correlation degree, the stronger the influence on the green development ability.

\subsection{Indicator Determination}

3.3.1. Construction of Indicator System. The construction of the index system needs to be systematic, objective, and scientific. According to the concept and connotation of urban green development, this paper constructs an index system for comprehensive evaluation of urban green development. Singh et al. [57] compile the indicators related to sustainable development, from the three aspects of economy, environment, and society and put forward the use of total wastewater, solid waste, network communications, and other indicators to evaluate the city's sustainable development level. 24 indicators were determined to evaluate the level of sustainable development, including observation indicators for soil, water, air, and other factors [58]. Oh et al. [59] found that the sustainable development capacity of cities is related to human activities, but the carrying capacity of cities is limited. Therefore, maintaining sustainable urban development requires coordination of input and output. For example, while using land, water, and other resources for production and development, increase the investment in technology management to control the generation of waste water and waste gas and improve the city's carrying capacity. Feng et al. [60] established an indicator system based on resource consumption and economic and social development and evaluated the green development transformation of Chinese cities in two stages of input and output.

The research in Table 1 constructs a green development evaluation index system mainly from the perspective of input and output. The input indicators include capital, labor, and energy consumption, and the output indicators include $\mathrm{GDP}, \mathrm{CO}_{2}$ emissions, and $\mathrm{SO}_{2}$ emissions. Therefore, referring to the above research results, this article mainly starts from the perspective of input and output to construct the evaluation index of green development of Chinese cities. 
TABLE 1: Research on evaluation index system of green development ability.

\begin{tabular}{|c|c|c|c|}
\hline Number & Author & Research area & Index \\
\hline 1 & $\begin{array}{l}\text { (Yuan et al.) } \\
\quad[61]\end{array}$ & $\begin{array}{l}\text { Shandong peninsula City } \\
\text { group, China }\end{array}$ & Resource input, nonresource input, ideal output and nonideal output \\
\hline 2 & $\begin{array}{l}\text { (Feng and } \\
\text { Wang) [62] }\end{array}$ & China & Energy, labor, capital, GDP, and carbon dioxide emissions \\
\hline 3 & (Qiu et al.) [63] & Xuzhou City group, China & $\begin{array}{l}\text { Investment in fixed assets, number of employees in the whole society, total } \\
\text { energy consumption, GDP, and industrial sulfur dioxide emissions }\end{array}$ \\
\hline 4 & (Zhu et al.) [64] & $\begin{array}{l}31 \text { provinces and cities in } \\
\text { mainland China }\end{array}$ & Capital stock, labor, energy consumption, GDP, and carbon dioxide emissions \\
\hline 5 & (Guo et al.) [65] & 34 cities in northeast China & $\begin{array}{l}\text { Construct evaluation indicators from the perspective of input-output, which } \\
\text { mainly include indicators such as capital, labor, resource consumption, } \\
\text { technological progress, economic development, industrial wastewater, industrial } \\
\qquad \mathrm{SO}_{2} \text {, and industrial dust }\end{array}$ \\
\hline 6 & (Ma et al.) [66] & $\begin{array}{l}285 \text { prefecture-level cities in } \\
\text { China }\end{array}$ & $\begin{array}{l}\text { From the perspective of input-output, the construction includes capital stock, } \\
\text { number of employees, total water supply, annual electricity consumption, GDP, } \\
\text { per capita disposable income, green coverage, public financial expenditure, } \\
\text { industrial wastewater discharge, } \mathrm{PM}_{2.5}, \mathrm{SO}_{2} \text {, the evaluation index system } \\
\text { including urban registered unemployment rate }\end{array}$ \\
\hline 7 & $\begin{array}{l}\text { (Feng et al.) } \\
\quad[67]\end{array}$ & 165 countries worldwide & Energy consumption, labor, capital, GDP, $\mathrm{SO}_{2}$ emissions, $\mathrm{CO}_{2}$ emissions \\
\hline 8 & (Pan et al.) [68] & China & Labor, energy consumption and capital stock, GDP, $\mathrm{CO}_{2}$ emissions \\
\hline 9 & $\begin{array}{l}\text { (Chen et al.) } \\
\text { [69] }\end{array}$ & China & $\begin{array}{l}\text { Constructed green development evaluation indicators including labor, capital, } \\
\text { energy consumption, expected output, and bad output. }\end{array}$ \\
\hline 10 & $\begin{array}{l}\text { (Shao et al.) } \\
{[70]}\end{array}$ & Shanghai, China & $\begin{array}{l}\text { Constructed input-output indicators including gross industrial output, capital, } \\
\text { labor, energy consumption, carbon emissions, etc. }\end{array}$ \\
\hline
\end{tabular}

Among them, green input evaluation indicators include two aspects: technology input and resource utilization; green output includes two aspects: environmental impact and economic impact.

The green investment evaluation index system includes technology investment and resource utilization. The technical input includes R\&D expenditure, fixed asset investment in the tertiary industry, number of research and development institutions, research and experimental development personnel, national science and technology awards, and amount of patent authorization. The green development of a city is related to the economic structure, and the increase in fixed investment in the tertiary industry can reflect the improvement of the economic development structure. At the same time, green and sustainable development is inseparable from technological innovation. $R \& D$ expenditures, the number of research and development institutions, research and test development personnel, national science and technology awards, and number of patent authorizations all reflect the city's scientific research and development in the development process. Support for technological innovation. Resource utilization includes total energy consumption, energy consumption per 10,000 yuan of GDP, comprehensive utilization of industrial solid waste, comprehensive utilization of industrial waste, and total water consumption. The total energy consumption, the energy consumption of 10,000 yuan of regional GDP, and the total water consumption can reflect the resource utilization and utilization efficiency of the city in development. The comprehensive utilization of industrial solid waste and the comprehensive utilization rate of industrial waste can reflect the city's ability in resource recycling.
The green output evaluation index system includes environmental and economic aspects. The city will produce economic benefits in the process of development, but it also affects the ecological environment. In terms of environment, the amount of industrial solid waste generated, the total amount of waste water discharge, and the amount of industrial waste gas emissions will damage the ecological environment, while increasing the amount of industrial solid waste disposal and forest coverage will have a positive impact on the ecological environment. The economic impact includes total GDP, technology market turnover, the added value of the tertiary industry, and the rate of decline in energy consumption for 10,000 yuan of regional GDP. The total GDP can reflect the level of economic development as a whole. The technological market turnover, the added value of the tertiary industry, and the rate of decline in energy consumption per 10,000 yuan of regional GDP can reflect the structure of economic growth and reflect the degree of urban green economy development. Table 2 summarizes the above evaluation indicators.

3.3.2. Data Sources. In order to ensure the authority and availability of the data, the data in this article come from "China City Statistical Yearbook (2010-2019)" and "China Regional Economic Statistics Yearbook (2010-2019).” The data for Beijing are also from the "Beijing Statistical Yearbook (2010-2019)," the data for Shanghai are from the "Shanghai Statistical Yearbook (2010-2019)," and the data for Shenzhen are from the "Shenzhen Statistical Yearbook (2010-2019)," Guangzhou City Data come from "Guangzhou Statistical Yearbook (2010-2019).” In addition, it also 
TABLe 2: Index system.

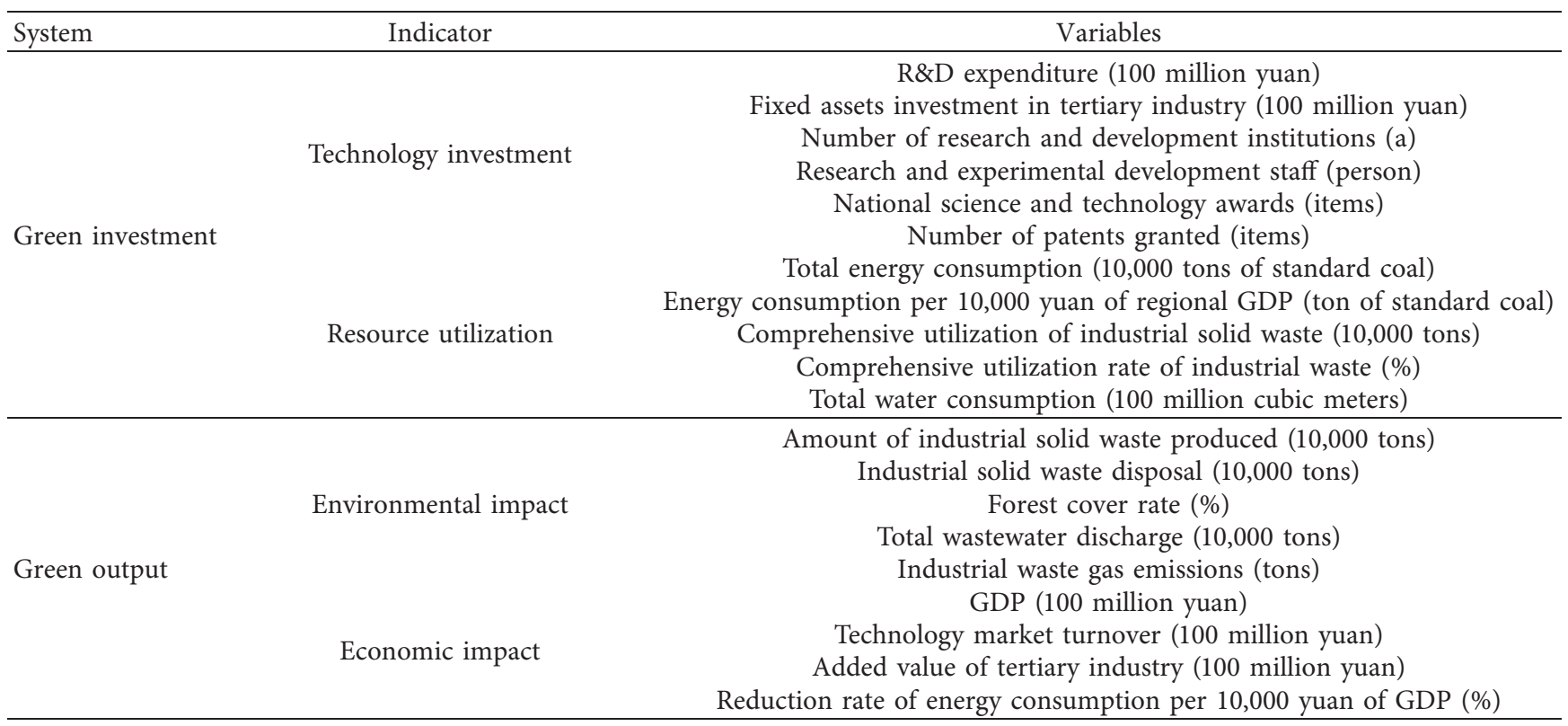

includes the statistical bulletins of economic and social development of various regions.

\section{Empirical Research}

4.1. Results of TOPSIS-BP Neural Network Model. According to the entropy TOPSIS method introduced above, this paper uses the panel data of Beijing, Shanghai, Shenzhen, and Guangzhou from 2009 to 2018 to calculate the green development level of Beijing, Shanghai, Shenzhen, and Guangzhou from 2009 to 2018. The calculation results are shown in Table 3.

After using the TOPSIS method to obtain the green development level of the four cities of Beijing, Shanghai, Shenzhen, and Guangzhou, this paper uses BP neural network to remodel and verify the results. Sun and Gao [71] used the Adaboost-BP neural network model when evaluating the potential energy-saving capabilities of China's power industry and believed that it was more accurate than conventional methods. Li et al. [72] used principal component analysis (PCA) and backpropagation (BP) neural network models to process factors and indicators to evaluate and analyze the development models of 35 smart cities in China. Therefore, using the TOPSIS-BP neural network model to evaluate and analyze the level of urban green development is more accurate and objective.

This paper has 40 samples of urban green development data, of which 36 samples are used as training sample data, and the other 4 sets of data are used as verification data. Firstly, use PyCharm as a coding tool and pytorch as a deep learning framework to build a BP neural network model. Perform data cleaning on the collected 40 data, delete the data with more null values, use the median method to insert some of the null values, and standardize the data to eliminate the differences between different characteristics. Second, build a model. This model uses 4 layers of neurons, of which the hidden layer is 2 . The input neurons are 19 , the number of
TABle 3: Test results based on the topsis model.

\begin{tabular}{lcccc}
\hline \multirow{2}{*}{ Years } & \multicolumn{4}{c}{ Test results } \\
& Beijing & Shanghai & Guangzhou & Shenzhen \\
\hline 2009 & 0.192 & 0.398 & 0.319 & 0.307 \\
2010 & 0.155 & 0.379 & 0.302 & 0.298 \\
2011 & 0.193 & 0.335 & 0.218 & 0.379 \\
2012 & 0.238 & 0.304 & 0.205 & 0.474 \\
2013 & 0.697 & 0.332 & 0.228 & 0.384 \\
2014 & 0.280 & 0.423 & 0.244 & 0.447 \\
2015 & 0.293 & 0.441 & 0.262 & 0.439 \\
2016 & 0.308 & 0.509 & 0.261 & 0.459 \\
2017 & 0.313 & 0.514 & 0.605 & 0.544 \\
2018 & 0.358 & 0.569 & 0.692 & 0.545 \\
\hline
\end{tabular}

neurons is 30 and 10 , and the output neuron is 1 , and the ReLU function is used as the activation function of the hidden layer. Increase the discreteness of the data, the learning rate is 0.0001 , and the number of training samples is 1000 .

Accurate and objective training samples can ensure the accuracy of output results to a greater extent. In order to ensure an objective and accurate evaluation of the regional green development capabilities, select the first 36 sample data among the 40 data as the training set. The input vector is $X=\left[X \_1, X \_2, \ldots, X \_36\right]$. According to the calculation result of the TOPSIS method as the output result of the neural network, the target output vector is $Y=\left[Y \_1, Y \_2, \ldots\right.$, $\left.Y \_36\right]$. After outputting the results, use Python's Matplotlib to compare the expected results with the real results. Table 3 shows the comparison between the actual value and the predicted value of the TOPSIS-BP neural network model.

Based on the measurement results of the TOPSIS-BP neural network model, the degree of fit between the actual value and the predicted value can be observed more intuitively from Figure 1. 


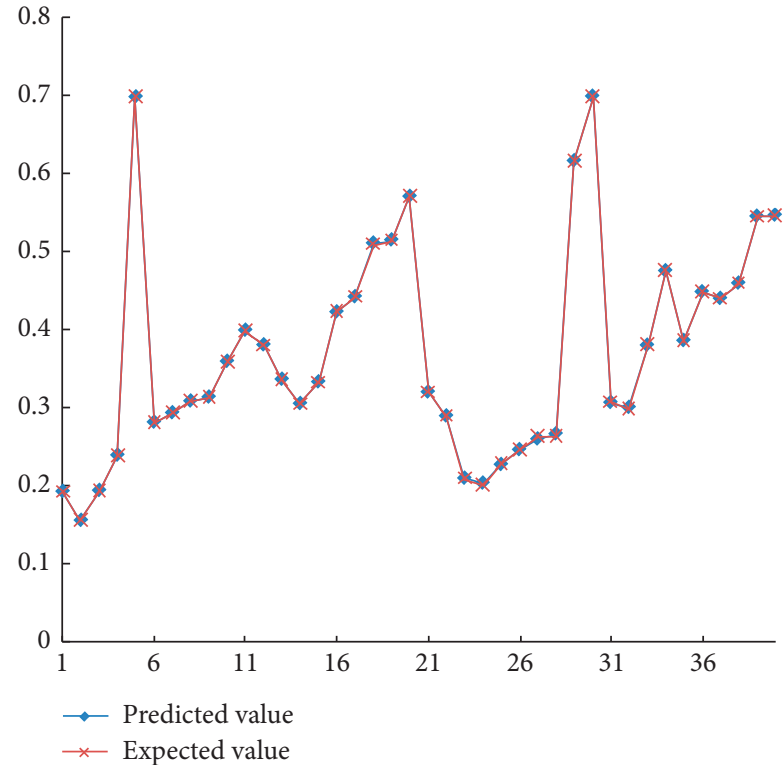

FIgURE 1: Fitting curve of the TOPSIS-BP neural network model.

Combining Table 4 and Figure 2, it can be seen that the actual value of the test sample fits the predicted value very well. The data calculated by TOPSIS and BP neural network models are consistent. Although there is a certain error, the error is small and the maximum error is 0.00423 . In addition, the data of the verification data are the actual value $(0.43888223,0.45845163,0.5440791,0.5455292)$, the predicted value $(0.438819,0.458668,0.543993,0.545479)$, and the error is small. It can be seen that when the BP neural network is used for evaluation, the influence of subjective factors is reduced to a certain extent, and it can effectively evaluate and analyze complex problems. Moreover, the trained BP neural network model can be retained, as long as the indicator data is input, the green development level of other cities can be tested.

4.2. Difference in Green Development Capabilities. Based on the collected sample data, after standardizing the original data, combined with the weighted Topsis-BP neural network model, the green development capabilities of Beijing, Shanghai, Guangzhou, and Shenzhen in 2009-2018 can be calculated. At the same time, the standard deviation and coefficient of variation are combined to measure the degree of difference in green development capabilities between different cities.

On the whole, the green development capabilities of Beijing, Shanghai, Shenzhen, and Guangzhou are improving in fluctuations, but different cities show different characteristics. From the perspective of development level, compared with Beijing and Guangzhou, Shanghai, and Shenzhen have higher green development capabilities, with the highest value appearing in 2018, reaching 0.569 and 0.545 , respectively. However, during the study period, Shanghai's green development ability experienced a process of decline first and then rise. The lowest value appeared in 2012, reaching 0.304. In fact, Shanghai is China's financial, trade, and
TABLE 4: Comparison of actual value and predicted value of the TOPSIS-BP neural network model.

\begin{tabular}{|c|c|c|c|}
\hline Years & Expected value & Predicted value & Relative error (\%) \\
\hline \multicolumn{4}{|c|}{ Beijing } \\
\hline 2009 & 0.1918 & 0.1918 & 0.0074 \\
\hline 2010 & 0.1548 & 0.1548 & 0.0258 \\
\hline 2011 & 0.1931 & 0.1931 & 0.0199 \\
\hline 2012 & 0.2381 & 0.2383 & 0.0498 \\
\hline 2013 & 0.6968 & 0.6968 & 0.0003 \\
\hline 2014 & 0.2803 & 0.2805 & 0.0739 \\
\hline 2015 & 0.2927 & 0.2925 & 0.0480 \\
\hline 2016 & 0.3077 & 0.3075 & 0.0416 \\
\hline 2017 & 0.3127 & 0.3126 & 0.0427 \\
\hline 2018 & 0.3584 & 0.3584 & 0.0009 \\
\hline \multicolumn{4}{|c|}{ Shanghai } \\
\hline 2009 & 0.3977 & 0.3982 & 0.1151 \\
\hline 2010 & 0.3789 & 0.3794 & 0.1469 \\
\hline 2011 & 0.3352 & 0.3354 & 0.0616 \\
\hline 2012 & 0.3042 & 0.3043 & 0.0549 \\
\hline 2013 & 0.3317 & 0.3320 & 0.1143 \\
\hline 2014 & 0.4226 & 0.4216 & 0.2325 \\
\hline 2015 & 0.4409 & 0.4410 & 0.0220 \\
\hline 2016 & 0.5086 & 0.5097 & 0.2247 \\
\hline 2017 & 0.5137 & 0.5137 & 0.0076 \\
\hline 2018 & 0.5694 & 0.5695 & 0.0161 \\
\hline \multicolumn{4}{|c|}{ Guangzhou } \\
\hline 2009 & 0.3190 & 0.3191 & 0.0399 \\
\hline 2010 & 0.2885 & 0.2885 & 0.0075 \\
\hline 2011 & 0.2085 & 0.2087 & 0.0970 \\
\hline 2012 & 0.2008 & 0.2025 & 0.8326 \\
\hline 2013 & 0.2274 & 0.2263 & 0.4907 \\
\hline 2014 & 0.2450 & 0.2453 & 0.1252 \\
\hline 2015 & 0.2632 & 0.2590 & 1.6083 \\
\hline 2016 & 0.2621 & 0.2655 & 1.3161 \\
\hline 2017 & 0.6150 & 0.6151 & 0.0240 \\
\hline 2018 & 0.6978 & 0.6977 & 0.0277 \\
\hline \multicolumn{4}{|c|}{ Shenzhen } \\
\hline 2009 & 0.3068 & 0.3057 & 0.3457 \\
\hline 2010 & 0.2981 & 0.2994 & 0.4331 \\
\hline 2011 & 0.3793 & 0.3790 & 0.0806 \\
\hline 2012 & 0.4743 & 0.4743 & 0.0099 \\
\hline 2013 & 0.3843 & 0.3849 & 0.1608 \\
\hline 2014 & 0.4474 & 0.4473 & 0.0106 \\
\hline 2015 & 0.4388 & 0.4389 & 0.0144 \\
\hline 2016 & 0.4587 & 0.4585 & 0.0472 \\
\hline 2017 & 0.5440 & 0.5441 & 0.0158 \\
\hline 2018 & 0.5455 & 0.5455 & 0.0092 \\
\hline
\end{tabular}

technological innovation center, with high-tech industries dominated by integrated circuits, software, and biomedicine, and strong green development capabilities. Shenzhen is a national logistics hub and an international technological industry innovation center, and the total number of PCT international patent applications has ranked first in the country for 14 consecutive years, which shows that technological innovation has a significant effect on improving the city's green development capabilities.

The green development capacity of Guangzhou has gone through three obvious stages. Among them, from 2009 to 2012 , the green development capacity declined year by year, but the rate of decline was relatively slow. From 2013 to 2016, 


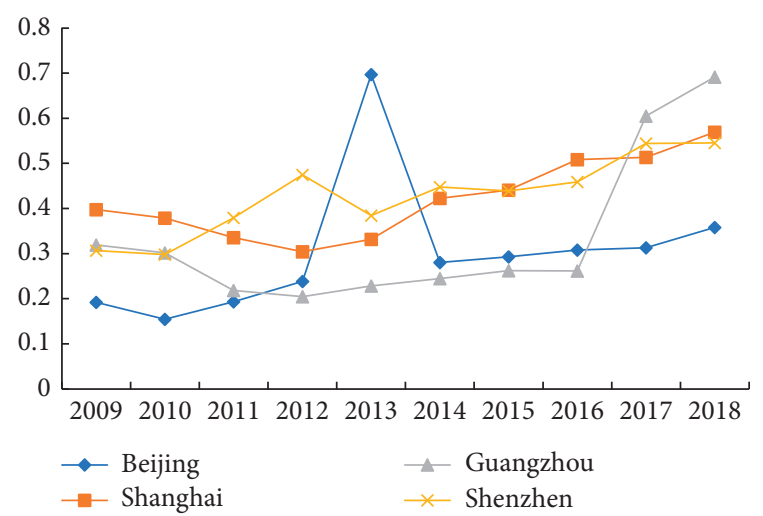

FIGURE 2: 2009-2018 Beijing, Shanghai, Shenzhen, and Guangzhou urban green development capabilities.

the green development capacity of Guangzhou was slowly improved, only from 0.228 to 0.261 . At this time, among the four cities, Guangzhou's green development capability is the last. After 2016, Guangzhou's green development capabilities have rapidly improved, with an average annual growth rate much higher than the other three cities, and in 2017-2018, the green development capabilities of the four cities ranked first. Beijing's green development capacity is slowly improving, reaching its peak in 2013, but its green development capacity is relatively low. In 2009-2011 and 2017-2018, the green development capacity was at the bottom of the first-tier cities.

It can be seen from Figure 3 that, on the whole, the urban green investment levels of Beijing, Shanghai, Shenzhen, and Guangzhou have risen in volatility, showing certain differences in different cities. During the study period, Beijing and Shanghai maintained a relatively high level of green investment, ranking first among the four cities in 2009-2011 and 2012-2016. Among these four cities, Guangzhou's green investment level was at the bottom between 2009 and 2016, and the improvement was extremely slow. There is a big gap with other cities. However, since 2016, Guangzhou's green investment level. It has been rapidly improved, and the level of green investment ranks first in the four cities. The level of green investment in Shenzhen has experienced a process of rising first, falling, and then slowly rising, showing a trend of volatility and rising overall. After 2017, the green investment level of the four cities has entered a flat phase.

In general, from 2009 to 2018, the green output levels of the four cities rose in fluctuations, and the green output levels of different cities have their own evolutionary trends in Figure 4. The level of green output in Beijing has always been lower than that of other cities, being the last of the four cities. But, in 2013, Beijing's green output level reached 0.751, ranking first among the four cities. The green output curve of Shanghai and Guangzhou showed a " $U$ " shape and experienced a process of first decline and then slowly increase, and both reached the maximum in 2018. Shenzhen's green output level was higher than other cities from 2011 to 2016, ranking first among the four cities, but after 2016, it showed a certain degree of downward trend.

Both the standard deviation and the coefficient of variation are indicators to measure the difference in green

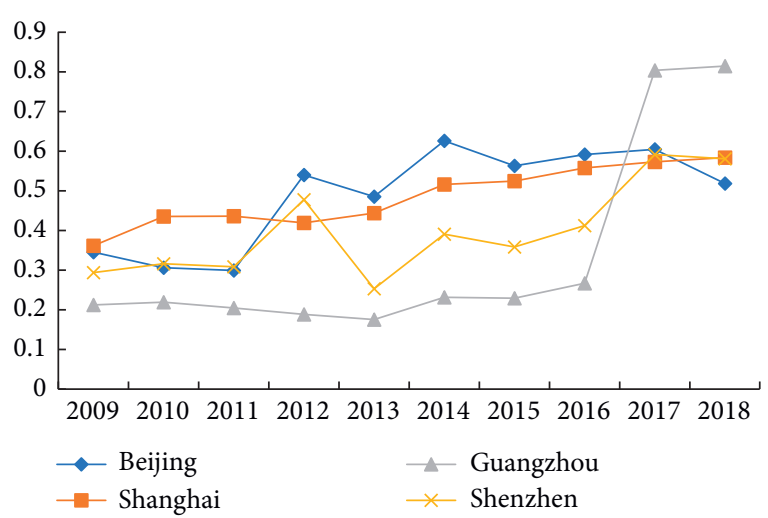

Figure 3: 2009-2018 Beijing, Shanghai, Shenzhen, and Guangzhou urban green investment.

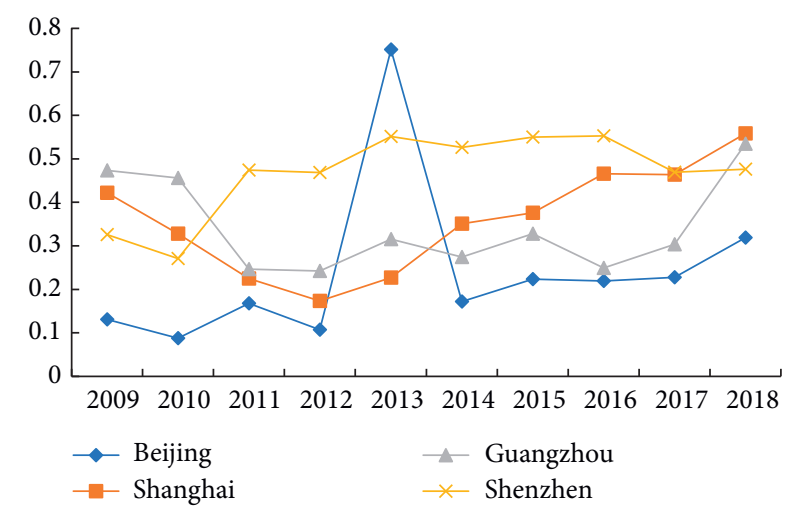

FIGURE 4: 2009-2018 Beijing, Shanghai, Shenzhen, and Guangzhou urban green output levels.

development capabilities between cities. On the whole, the standard deviation and the coefficient of variation showed a similar evolutionary trend, and both experienced a process of first becoming larger and then becoming smaller in Figure 5. From 2009 to 2013, the standard deviation and the coefficient of variation increased year by year, indicating that the difference in urban green development capabilities is gradually expanding. From 2014 to 2018, the standard deviation and coefficient of variation decreased year by year, indicating that the difference in green development capabilities between cities is gradually shrinking. In fact, since 2014, China's economy has gradually entered the "new normal," from factor-driven and investment-driven to innovation-driven, not only the role of emerging industries, service industries, and small and microenterprises, but also the manufacturing of steel, cement, electrolytic aluminum, etc. The industry has gradually realized "de-capacity," and the problems of resource waste and environmental pollution have been gradually solved, which has gradually reduced the green development gap between cities.

4.3. Influencing Factors of the Urban Green Development Level. Studying the influencing factors of the green development capacity of Beijing, Shanghai, Shenzhen, and Guangzhou is of great significance for how to improve the 


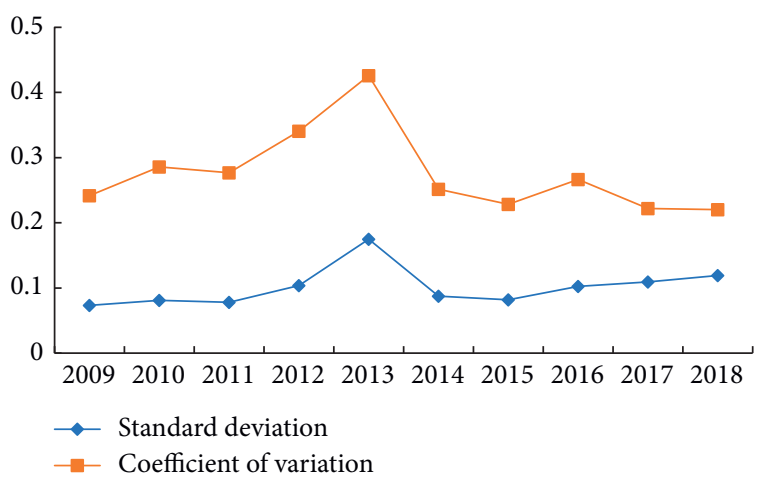

FIGURE 5: 2009-2018 Beijing, Shanghai, Shenzhen, and Guangzhou urban green development level difference index.

green development capacity and realize the sustainable development of the region. Therefore, using the grey correlation analysis method, according to the size of the gray correlation coefficient of each element, filter out the factors that affect the green development ability. It can be found that there are obvious temporal and spatial differences in the factors affecting the green development capacity in 2009-2018.

Under the same time series, the factors affecting the green development capabilities of Beijing, Shanghai, Guangzhou, and Shenzhen show certain differences. From Table 5, it can be found that, from 2009 to 2013, the factors affecting the green development capacity of the four major cities were quite different. Among them, the amount of patent authorization and industrial waste gas emissions are the primary factors affecting the improvement of the green development capabilities of Beijing and Shenzhen. The total energy consumption is the primary factor that affects the improvement of the green development capacity of Shanghai and Guangzhou, and the last influential factors have different degrees of influence on the green development capacity of different cities. Forest coverage, fixed asset investment in the tertiary industry, research and experimental development personnel, and number of research and development institutions are the last factors affecting the green development capabilities of Beijing, Shanghai, Guangzhou, and Shenzhen, respectively. At the same time, the same influencing factor has different degrees of importance to different cities. The number of research and development institutions has a second place in the influence of Guangzhou, but the influence on Shenzhen is in the 20th place. The impact of industrial waste gas emissions on Shenzhen ranks first, but the impact on Shanghai ranks 19th.

It can be seen from Table 6, compared with 2009-2013, the factors affecting the green development capabilities of the four major cities in 2014-2018 are still quite different. Among them, research and experimental development personnel are the primary factor affecting the improvement of Beijing and Shanghai's green development capabilities. The number of patent authorizations and the transaction volume of technology contracts are the factors affecting the improvement of the green development capabilities of Guangzhou and Shenzhen. The national science and technology awards and the comprehensive utilization of industrial solid waste are the last factors affecting the green development capabilities of Beijing and Shanghai, respectively. Industrial waste gas emissions are the last factors affecting the green development capabilities of Guangzhou and Shenzhen. At the same time, the same influencing factor has different degrees of importance to different cities. Research and experimental development personnel are the first factor that affects the green development capabilities of Beijing and Shanghai, but the impact on Guangzhou ranks 15th. The influence of technology contract turnover on Shenzhen ranks first, but the influence on Shanghai ranks 12 th.

As the time series change, the factors that affect the green development capability of the same city are also changing. From 2009 to 2018, the primary factor affecting Beijing's green development capabilities changed from the number of patents granted to the number of research and experimental development personnel; the primary factor influencing Shanghai's green development capability has changed from total energy consumption to the number of research and experimental development personnel; the primary factor affecting Guangzhou's green development capabilities has changed from total energy consumption to the number of patents granted; the primary factor affecting Shenzhen's green development capabilities has changed from industrial waste gas emissions to technical contract turnover.

In the two time periods of 2009-2013 and 2014-2018, the number of patent grants, research and experimental development personnel, technology contract turnover, tertiary industry fixed asset investment, tertiary industry added value, and total energy consumption have appeared more than 3 times in the top 5 influencing factors in 4 cities. This shows that attaching importance to scientific and technological innovation, reducing unit energy consumption, and improving resource utilization are particularly important for improving green development capabilities.

\section{Discussion}

This article builds on the evaluation index system for the green development capability of four cities in Beijing, Shanghai, Shenzhen, and Guangzhou, based on the panel data published by each city in 2009-2018. The article combines entropy method, weighted topsis, and BP neural network to measure the green development capacity, green input level, and green output level of these four cities from 2009 to 2018. And, on this basis, the green development level of the four cities and the green development differences between the cities are analyzed, and then the grey correlation analysis method is used to identify the factors that affect the green development of the city.

The research results show that, first, the urban green development level of Beijing, Shanghai, Shenzhen, and Guangzhou has improved significantly, but there are obvious temporal and spatial differences. Among them, the green development capacity of Shanghai and Shenzhen is relatively higher than that of Beijing and Guangzhou. The green development capacity of Guangzhou has improved the 
TABLE 5: 2009-2013 grey correlation coefficient of urban green development ability of Beijing, Shanghai, Shenzhen, and Guangzhou.

\begin{tabular}{|c|c|c|c|c|c|c|c|c|}
\hline Variables & Beijing & Rank & Shanghai & Rank & Guangzhou & Rank & Shenzhen & Rank \\
\hline $\mathrm{R} \& \mathrm{D}$ expenditure & 0.780 & 6 & 0.633 & 17 & 0.501 & 19 & 0.675 & 9 \\
\hline Fixed assets investment in tertiary industry & 0.801 & 3 & 0.617 & 20 & 0.557 & 11 & 0.699 & 7 \\
\hline Number of research and development institutions & 0.747 & 12 & 0.686 & 11 & 0.830 & 2 & 0.579 & 20 \\
\hline Research and experimental development staff & 0.769 & 9 & 0.689 & 10 & 0.454 & 20 & 0.715 & 5 \\
\hline National science and technology awards & 0.674 & 17 & 0.901 & 2 & 0.518 & 18 & 0.629 & 15 \\
\hline Number of patents granted & 0.806 & 1 & 0.751 & 6 & 0.530 & 14 & 0.715 & 4 \\
\hline Total energy consumption & 0.726 & 15 & 0.903 & 1 & 0.911 & 1 & 0.736 & 3 \\
\hline Energy consumption per 10,000 yuan of regional GDP & 0.701 & 16 & 0.684 & 12 & 0.544 & 12 & 0.659 & 12 \\
\hline Comprehensive utilization of industrial solid waste & 0.769 & 10 & 0.871 & 3 & 0.785 & 3 & 0.615 & 18 \\
\hline Comprehensive utilization rate of industrial waste & 0.777 & 8 & 0.837 & 4 & 0.685 & 5 & 0.663 & 11 \\
\hline Total water consumption & 0.778 & 7 & 0.743 & 7 & 0.618 & 10 & 0.765 & 2 \\
\hline Amount of industrial solid waste produced & 0.733 & 14 & 0.630 & 18 & 0.527 & 15 & 0.649 & 13 \\
\hline Industrial solid waste disposal & 0.667 & 18 & 0.740 & 8 & 0.666 & 6 & 0.617 & 17 \\
\hline Forest cover rate & 0.611 & 20 & 0.761 & 5 & 0.643 & 8 & 0.580 & 19 \\
\hline Total wastewater discharge & 0.737 & 13 & 0.695 & 9 & 0.745 & 4 & 0.685 & 8 \\
\hline Industrial waste gas emissions & 0.756 & 11 & 0.623 & 19 & 0.634 & 9 & 0.781 & 1 \\
\hline GDP & 0.784 & 4 & 0.656 & 15 & 0.524 & 17 & 0.703 & 6 \\
\hline Technology market turnover & 0.802 & 2 & 0.660 & 13 & 0.536 & 13 & 0.623 & 16 \\
\hline Added value of tertiary industry & 0.782 & 5 & 0.655 & 16 & 0.525 & 16 & 0.671 & 10 \\
\hline Reduction rate of energy consumption per 10,000 yuan of GDP & 0.658 & 19 & 0.657 & 14 & 0.645 & 7 & 0.649 & 14 \\
\hline
\end{tabular}

TABle 6: 2014-2018 China's first-tier cities' green development capacity grey correlation coefficient.

\begin{tabular}{|c|c|c|c|c|c|c|c|c|}
\hline Variables & Beijing & Rank & Shanghai & Rank & Guangzhou & Rank & Shenzhen & Rank \\
\hline R\&D expenditure & 0.899 & 7 & 0.841 & 10 & 0.851 & 4 & 0.693 & 5 \\
\hline Fixed assets investment in tertiary industry & 0.913 & 4 & 0.851 & 9 & 0.784 & 9 & 0.698 & 3 \\
\hline Number of research and development institutions & 0.870 & 11 & 0.922 & 3 & 0.818 & 8 & 0.684 & 9 \\
\hline Research and experimental development staff & 0.929 & 1 & 0.982 & 1 & 0.655 & 15 & 0.680 & 13 \\
\hline National science and technology awards & 0.598 & 20 & 0.609 & 16 & 0.784 & 10 & 0.655 & 15 \\
\hline Number of patents granted & 0.919 & 3 & 0.776 & 11 & 0.874 & 1 & 0.719 & 2 \\
\hline Total energy consumption & 0.724 & 13 & 0.494 & 19 & 0.578 & 19 & 0.621 & 19 \\
\hline Energy consumption per 10,000 yuan of regional GDP & 0.921 & 2 & 0.967 & 2 & 0.781 & 11 & 0.681 & 12 \\
\hline Comprehensive utilization of industrial solid waste & 0.622 & 18 & 0.462 & 20 & 0.745 & 12 & 0.623 & 17 \\
\hline Comprehensive utilization rate of industrial waste & 0.676 & 17 & 0.577 & 17 & 0.655 & 16 & 0.622 & 18 \\
\hline Total water consumption & 0.902 & 5 & 0.691 & 14 & 0.839 & 6 & 0.688 & 8 \\
\hline Amount of industrial solid waste produced & 0.870 & 10 & 0.912 & 4 & 0.662 & 14 & 0.684 & 10 \\
\hline Industrial solid waste disposal & 0.677 & 16 & 0.620 & 15 & 0.627 & 18 & 0.665 & 14 \\
\hline Forest cover rate & 0.763 & 12 & 0.878 & 6 & 0.851 & 3 & 0.693 & 6 \\
\hline Total wastewater discharge & 0.690 & 15 & 0.894 & 5 & 0.727 & 13 & 0.684 & 11 \\
\hline Industrial waste gas emissions & 0.715 & 14 & 0.508 & 18 & 0.504 & 20 & 0.566 & 20 \\
\hline GDP & 0.900 & 6 & 0.866 & 8 & 0.828 & 7 & 0.692 & 7 \\
\hline Technology market turnover & 0.886 & 9 & 0.723 & 12 & 0.855 & 2 & 0.749 & 1 \\
\hline Added value of tertiary industry & 0.895 & 8 & 0.867 & 7 & 0.847 & 5 & 0.694 & 4 \\
\hline Reduction rate of energy consumption per 10,000 yuan of GDP & 0.620 & 19 & 0.697 & 13 & 0.644 & 17 & 0.643 & 16 \\
\hline
\end{tabular}

fastest, from the last in 2012-2016 to the first after 2017. Second, the green input level and green output level are increasing in fluctuation, but there are obvious differences. Among them, the green input level of Beijing is basically at the forefront of the four cities, but the green output level is basically at the bottom. Third, the differences in green development among Beijing, Shanghai, Shenzhen, and Guangzhou have experienced a process of first expanding and then shrinking. Among them, the entry of China's economy into a new normal has played an important role in reducing the differences in green development between cities. Fourth, under the same time series, the factors affecting the green development capabilities of Beijing, Shanghai, Guangzhou, and Shenzhen show certain differences. In addition, as the time series changes, the factors that affect the green development capability of the same city are also changing. Among them, the primary factors affecting the green development capabilities of Beijing and Shanghai have changed from the number of patent authorizations and total energy consumption to the number of research and experimental development personnel. The primary factors affecting the green development capabilities of Guangzhou and Shenzhen have changed from total energy consumption and industrial waste gas emissions to patent authorization 
and technology contract turnover. It can be seen from these changes that technological innovation and resource utilization efficiency are becoming more and more important to the level of urban green development and have become the main influencing factors.

\section{Conclusion}

The sustained and rapid development of the national economy has driven the rapid development of cities. However, in the process of urban development, problems such as resource waste and environmental pollution will inevitably arise. Urban green development is conducive to improving the competitiveness of cities and coordinating the relationship between economic development and environmental society. Therefore, urban green development will become a trend. This paper establishes an index system to evaluate the level of urban green development, uses the TOPSIS-BP neural network model to model the green development levels of Beijing, Shanghai, Shenzhen, and Guangzhou, and use grey correlation to analyze the factors that affect the level of urban green development. It is found that, in the process of urban green development, green technology innovation has played an important role.

There are several main contributions of this article, first of all the theoretical significance: firstly, the current research on urban green and sustainable development mainly focuses on the planning of urban land resources and the protection of the ecological environment from a macroperspective [73-76]. This article analyzes the specific factors that affect the level of urban green development and to some extent makes up for the lack of analysis of specific factors that affect the level of urban green development in existing studies. Secondly, the connotation of regional differences enriched and expanded. As each city has different resource endowments, resource allocation, location conditions, and external environment, this will inevitably cause differences between regions [77-79]. In fact, this article uses the gray relational analysis method to find that, under the same time series, the factors affecting the green development capabilities of Beijing, Shanghai, Guangzhou, and Shenzhen show certain differences. This shows that there are differences in green development capabilities among different regions and further proves that regional differences exist objectively and enriches the connotation of regional differences.

At the same time, this article also has certain practical significance. Firstly, this article uses the topsis-bp neural network model to evaluate and analyze the level of urban green development, which is more accurate and objective. BP neural network has good learning ability and can provide certain theoretical and practical reference for evaluating the green development level of other cities. In addition, the article constructs an evaluation index system for urban green development from the perspective of input and output. This index system takes into account the economic and environmental impacts of technological input and resource utilization, and can scientifically measure the level of green development. First-tier cities such as Beijing, Shanghai, Guangzhou, and Shenzhen can formulate relevant policies based on this indicator system to improve their green development capabilities. Finally, the research samples are Beijing, Shanghai, Shenzhen, and Guangzhou, four developed cities in China. These four cities are in a leading position in mainland China in terms of economic strength and scientific research strength. This is also of important reference value for the formulation of green development policies in other regions.

In response to the above research conclusions, in order to promote the improvement of China's urban green development capabilities, this article makes the following recommendations:

First, increase investment in science and technology and green technology innovation. From the data analysis results of the article, compared with energy consumption and "three wastes" emissions, green technology innovation has increasingly become an important factor in the process of urban green development. In addition, technological innovation can effectively improve production efficiency and reduce energy consumption, which is of great significance to the development of green cities. Cai and Shang [80] believe that advances in science and technology are conducive to enhancing the carrying capacity of urban ecosystems, thereby improving the level of green development of cities. $\mathrm{Li}$ and Luo [81] believe that science and technology have become an important factor affecting sustainable development. Fang et al. [82] found that sufficient technical support plays a key role in improving the sustainable development of cities, improving the ecological environment, and developing green cities.

Second, establish and improve laws and policies related to urban green development and establish a sense of green development. Production and living activities have an important influence on the development of the city. Strengthening the supervision of production activities can reduce to a certain extent the behaviors of enterprises and production units that undermine the green development of cities. The improvement of the public's awareness of green development can to a certain extent enhance residents' willingness to live a green lifestyle and can also increase the public's participation in government green management and strengthen the supervision of economic activities. Hawkins and Wang [83] found on the basis of a national survey of the United States that government initiatives and increased public willingness to participate are essential to the urban ecological environment and sustainable development.

Finally, improve resource utilization and develop a green economy. To realize the green development of the city, it is necessary to coordinate the development of the city with the resources and the environment. That is to say, how to scientifically use limited resources, improve the utilization rate of resources, and develop a green economy is of vital importance to the green development of the city. Wang et al. [84] studied the green development of 9 cities in the Pearl River Delta and proposed that urban green development should improve the energy utilization structure and build a low-carbon recycling industry system.

This paper mainly uses the TOPSIS-BP neural network model to evaluate the green development level of four cities 
in Beijing, Shanghai, Shenzhen, and Guangzhou and analyzes the factors that affect the city's green development level through grey correlation analysis methods. This article has certain rationality and objectivity in the research content and research methods. But, this article still has some shortcomings: first of all, the development of some cities has regional characteristics, and the green development of cities is also unique. The sample areas selected in this article may bring greater reference significance to economically developed areas and lack a certain degree of universal adaptation. Secondly, due to the high authenticity required for data collection, the indicators selected in this article are all quantitative indicators to ensure the authenticity and accuracy of the data. However, adding some qualitative indicators will help measure the level of urban green development more comprehensively. Future research will also focus on the impact of qualitative indicators on the level of urban green development, expand the scope of research, and increase the universality of research.

\section{Conflicts of Interest}

The authors declare that there are no conflicts of interest regarding the publication of this article.

\section{Acknowledgments}

This work was supported by the National Natural Science Foundation of China (Grant nos. 71804056, 71672111, 71932004, and 71803197), Humanities and Social Sciences Research Project of the Ministry of Education of China (18YJC630250 and 18YJC630094), China Postdoctoral Science Foundation (2018M642033), the Fundamental Research Funds for the Central Universities (31511910801), and Soft Science Project of Technological Innovation in Hubei Province (2019ADC029).

\section{References}

[1] S. Campbell, "Green cities, growing cities, just cities?: urban planning and the contradictions of sustainable development," Journal of the American Planning Association, vol. 62, no. 3, pp. 296-312, 1996.

[2] M. Yokohari, K. Takeuchi, T. Watanabe, and S. Yokota, "Beyond greenbelts and zoning: a new planning concept for the environment of Asian mega-cities," in Urban Ecology, pp. 783-796, Springer, Berlin, Germany, 2008.

[3] A. Van Herzele and T. Wiedemann, "A monitoring tool for the provision of accessible and attractive urban green spaces," Landscape and Urban Planning, vol. 63, no. 2, pp. 109-126, 2003.

[4] V. D. B. M. Annerstedt, P. Mudu, V. Uscila et al., "Development of an urban green space indicator and the public health rationale," Scandinavian Journal of Public Health, vol. 44, pp. 159-167, 2016.

[5] K. Horwood, "Green infrastructure: reconciling urban green space and regional economic development: lessons learnt from experience in England's north-west region," Local Environment, vol. 16, no. 10, pp. 963-975, 2011.

[6] E. Andersson, S. Barthel, S. Borgström et al., "Reconnecting cities to the biosphere: stewardship of green infrastructure and urban ecosystem services," Ambio, vol. 43, no. 4, pp. 445-453, 2014.

[7] U. G. Sandström, P. Angelstam, and A. Khakee, "Urban comprehensive planning_identifying barriers for the maintenance of functional habitat networks," Landscape and Urban Planning, vol. 75, no. 1-2, pp. 43-57, 2006.

[8] K. H. Thorén, "“The green poster" a method to evaluate the sustainability of the urban green structure," Environmental Impact Assessment Review, vol. 20, no. 3, pp. 359-371, 2000.

[9] G. H. Brundtland, M. Khalid, S. Agnelli, S. Al-Athel, and B. Chidzero, Our Common Future, Vol. 8, Oxford University Press, Oxford, UK, 1987.

[10] J. Zhang, Y. Chang, L. Zhang, and D. Li, "Do technological innovations promote urban green development? - a spatial econometric analysis of 105 cities in China," Journal of Cleaner Production, vol. 182, pp. 395-403, 2018.

[11] P. Jin, C. Peng, and M. Song, "Macroeconomic uncertainty, high-level innovation, and urban green development performance in China," China Economic Review, vol. 55, pp. 1-18, 2019.

[12] M. Artmann, L. Inostroza, and P. Fan, Urban Sprawl, Compact Urban Development and Green Cities. How Much Do We Know, How Much Do We Agree?, Elsevier, Amsterdam, Netherlands, 2019.

[13] S. L. Zhao, W. Song, D. Y. Zhu, X. B. Peng, and W. Cai, "Evaluating China's regional collaboration innovation capability from the innovation actors perspective-an AHP and cluster analytical approach," Technology in Society, vol. 35, no. 3, pp. 182-190, 2013.

[14] K. Li and B. Lin, "Impact of energy conservation policies on the green productivity in China's manufacturing sector: evidence from a three-stage DEA model," Applied Energy, vol. 168, pp. 351-363, 2016.

[15] Y. Duan, H. Mu, N. Li, L. Li, and Z. Xue, "Research on comprehensive evaluation of low carbon economy development level based on AHP-entropy method: a case study of Dalian," Energy Procedia, vol. 104, pp. 468-474, 2016.

[16] H. F. Tong, Y. Yang, J. Y. Wang, and Y. Feng, "Modeling China's green economy 2050: scenario analysis based on the system dynamics model," China Soft Science, vol. 6, pp. 20-34, 2015.

[17] M. Jacobs, The Green Economy: Environment, Sustainable Development and the Politics of the Future, UBC Press, Vancouver, Canada, 1993.

[18] S. M. A. Haq, "Urban green spaces and an integrative approach to sustainable environment," Journal of Environmental Protection, vol. 2, no. 5, p. 601, 2011.

[19] M. Budruk, H. Thomas, and T. Tyrrell, "Urban green spaces: a study of place attachment and environmental attitudes in India," Society \& Natural Resources, vol. 22, no. 9, pp. 824-839, 2009.

[20] J. R. Wolch, J. Byrne, and J. P. Newell, "Urban green space, public health, and environmental justice: the challenge of making cities "just green enough," Landscape and Urban Planning, vol. 125, pp. 234-244, 2014.

[21] X. Dou, S. Li, and J. Wang, "Ecological strategy of city sustainable development," APCBEE Procedia, vol. 5, pp. 429-434, 2013.

[22] J. Wu, W. Xiang, and J. Zhao, "Urban ecology in China: historical developments and future directions," Landscape and Urban Planning, vol. 125, pp. 222-233, 2014.

[23] J. Niemelä, S.-R. Saarela, T. Söderman et al., "Using the ecosystem services approach for better planning and conservation of urban green spaces: a Finland case study," 
Biodiversity and Conservation, vol. 19, no. 11, pp. 3225-3243, 2010.

[24] M. F. Aronson, C. A. Lepczyk, K. L. Evans et al., "Biodiversity in the city: key challenges for urban green space management," Frontiers in Ecology and the Environment, vol. 15, no. 4, pp. 189-196, 2017.

[25] P. Dicken, Global Shift: Reshaping the Global Economic Map in the 21st Century, Sage, Thousand Oaks, CA, USA, 2003.

[26] W. E. Rees, "Ecological footprints and appropriated carrying capacity: what urban economics leaves out," Environment and Urbanization, vol. 4, no. 2, pp. 121-130, 1992.

[27] N. Dempsey, G. Bramley, S. Power, and C. Brown, "The social dimension of sustainable development: defining urban social sustainability," Sustainable Development, vol. 19, no. 5, pp. 289-300, 2011.

[28] N. Heynen, "Urban political ecology," International Encyclopedia of Geography: People, the Earth, Environment and Technology: People, the Earth, Environment and Technology, pp. 1-9, John Wiley \& Sons, Hoboken, NJ, USA, 2016.

[29] S. Yin and B. Li, "Academic research institutes-construction enterprises linkages for the development of urban green building: selecting management of green building technologies innovation partner," Sustainable Cities and Society, vol. 48, Article ID 101555, 2019.

[30] S. Pauleit, B. Ambrose-Oji, E. Andersson et al., "Advancing urban green infrastructure in Europe: outcomes and reflections from the GREEN SURGE project," Urban Forestry \& Urban Greening, vol. 40, pp. 4-16, 2019.

[31] Z. S. Venter, C. M. Shackleton, F. Van Staden, O. Selomane, and V. A. Masterson, "Green Apartheid: urban green infrastructure remains unequally distributed across income and race geographies in South Africa," Landscape and Urban Planning, vol. 203, Article ID 103889, 2020.

[32] S. Barles, "Society, energy and materials: the contribution of urban metabolism studies to sustainable urban development issues," Journal of Environmental Planning and Management, vol. 53, no. 4, pp. 439-455, 2010.

[33] W. Y. Chen and D. T. Wang, "Economic development and natural amenity: an econometric analysis of urban green spaces in China," Urban Forestry \& Urban Greening, vol. 12, no. 4, pp. 435-442, 2013.

[34] F. Li, X. Liu, D. Hu et al., "Measurement indicators and an evaluation approach for assessing urban sustainable development: a case study for China's Jining city," Landscape and Urban Planning, vol. 90, no. 3-4, pp. 134-142, 2009.

[35] D. Guan, W. Gao, W. Su, H. Li, and K. Hokao, "Modeling and dynamic assessment of urban economy-resource-environment system with a coupled system dynamics-geographic information system model," Ecological Indicators, vol. 11, no. 5, pp. 1333-1344, 2011.

[36] N. X. Thinh, G. Arlt, B. Heber, J. Hennersdorf, and I. Lehmann, "Evaluation of urban land-use structures with a view to sustainable development," Environmental Impact Assessment Review, vol. 22, no. 5, pp. 475-492, 2002.

[37] N. Wang, J. C. K. Lee, J. Zhang, H. Chen, and H. Li, "Evaluation of urban circular economy development: an empirical research of 40 cities in China," Journal of Cleaner Production, vol. 180, pp. 876-887, 2018.

[38] L. Ding, Z. Shao, H. Zhang, C. Xu, and D. Wu, "A comprehensive evaluation of urban sustainable development in China based on the TOPSIS-entropy method," Sustainability, vol. 8, no. 8, p. 746, 2016.

[39] B. Meng, L. Zhou, L. Qu, and M. Z. Abedin, "Measurement of urban green economy development-an empirical analysis from 31 provinces in China," Ekoloji, vol. 28, pp. 2069-2082, 2019.

[40] L. Lin and L. Ying, "A dynamic evaluation on and comparison between the green efficiency of the central delta urban agglomeration and the Yangtze river delta urban agglomeration," Journal of Jiangxi University of Finance and Economics, vol. 3, pp. 3-12, 2015.

[41] S. Zheng, R. Wang, E. L. Glaeser, and M. E. Kahn, "The greenness of China: household carbon dioxide emissions and urban development," Journal of Economic Geography, vol. 11, no. 5, pp. 761-792, 2011.

[42] M. E. Kahn, Green Cities: Urban Growth and the Environment, Brookings Institution Press, Washington, DC, USA, 2007.

[43] Y. X. He, Z. Jiao, and J. Yang, "Comprehensive evaluation of global clean energy development index based on the improved entropy method," Ecological Indicators, vol. 88, pp. 305-321, 2018.

[44] R. Rubinstein, "The cross-entropy method for combinatorial and continuous optimization," Methodology and Computing in Applied Probability, vol. 1, no. 2, pp. 127-190, 1999.

[45] J. Zhao, G. Ji, Y. Tian, Y. Chen, and Z. Wang, "Environmental vulnerability assessment for mainland China based on entropy method," Ecological Indicators, vol. 91, pp. 410-422, 2018.

[46] L.-y. Sun, C.-1. Miao, and L. Yang, "Ecological-economic efficiency evaluation of green technology innovation in strategic emerging industries based on entropy weighted TOPSIS method," Ecological Indicators, vol. 73, pp. 554-558, 2017.

[47] K. Rashidi and K. Cullinane, "A comparison of fuzzy DEA and fuzzy TOPSIS in sustainable supplier selection: implications for sourcing strategy," Expert Systems with Applications, vol. 121, pp. 266-281, 2019.

[48] B. M. Dos Santos, L. P. Godoy, and L. M. S. Campos, "Performance evaluation of green suppliers using entropyTOPSIS-F," Journal of Cleaner Production, vol. 207, pp. 498-509, 2019.

[49] Z. Wang, H. Hao, F. Gao, Q. Zhang, J. Zhang, and Y. Zhou, "Multi-attribute decision making on reverse logistics based on DEA-TOPSIS: a study of the Shanghai end-of-life vehicles industry," Journal of Cleaner Production, vol. 214, pp. 730737, 2019.

[50] S. E. Fahlman, An Empirical Study of Learning Speed in BackPropagation Networks, Carnegie Mellon University, Computer Science Department, Pittsburgh, PA, USA, 1988.

[51] L. Peng and L. Lai, "A service innovation evaluation framework for tourism e-commerce in China based on BP neural network," Electronic Markets, vol. 24, no. 1, pp. 37-46, 2014.

[52] S. Li and Q. Wang, "India's dependence on foreign oil will exceed $90 \%$ around 2025-the forecasting results based on two hybridized NMGM-ARIMA and NMGM-BP models," Journal of Cleaner Production, vol. 232, pp. 137-153, 2019.

[53] R. Zhang, Y. Wang, K. Wang et al., "An evaluating model for smart growth plan based on BP neural network and set pair analysis," Journal of Cleaner Production, vol. 226, pp. 928-939, 2019.

[54] V. Bobinaite, A. Juozapaviciene, M. Staniewski, and P. Szczepankowski, "Comparative analysis of features of Polish and Lithuanian day-ahead electricity market prices," Energy Policy, vol. 63, pp. 181-196, 2013.

[55] Y. Huang, L. Shen, and H. Liu, "Grey relational analysis, principal component analysis and forecasting of carbon emissions based on long short-term memory in China," Journal of Cleaner Production, vol. 209, pp. 415-423, 2019. 
[56] Q. Sun and Y. Tang, "The grey relational degree measurement of city's S\&T input and sustainable economic development based on the data from Hunan province," Procedia Engineering, vol. 21, pp. 457-463, 2011.

[57] R. K. Singh, H. R. Murty, S. K. Gupta, and A. K. Dikshit, "An overview of sustainability assessment methodologies," Ecological Indicators, vol. 9, no. 2, pp. 189-212, 2009.

[58] Y. Xing, R. M. W. Horner, M. A. El-Haram, and J. Bebbington, "A framework model for assessing sustainability impacts of urban development," in Accounting Forum, pp. 209-224, Elsevier, Amsterdam, Netherlands, 2009.

[59] K. Oh, Y. Jeong, D. Lee, W. Lee, and J. Choi, "Determining development density using the urban carrying capacity assessment system," Landscape and Urban Planning, vol. 73, no. 1, pp. 1-15, 2005.

[60] Y. Feng, X. Dong, X. Zhao, and A. Zhu, "Evaluation of urban green development transformation process for Chinese cities during 2005-2016," Journal of Cleaner Production, vol. 266, Article ID 121707, 2020.

[61] W. Yuan, J. Li, L. Meng, X. Qin, and X. Qi, "Measuring the area green efficiency and the influencing factors in urban agglomeration," Journal of Cleaner Production, vol. 241, Article ID 118092, 2019.

[62] C. Feng and M. Wang, "The heterogeneity of China's pathways to economic growth, energy conservation and climate mitigation," Journal of Cleaner Production, vol. 228, pp. 594-605, 2019.

[63] F. Qiu, Y. Chen, J. Tan, J. Liu, Z. Zheng, and X. Zhang, "Spatial-temporal heterogeneity of green development efficiency and its influencing factors in growing metropolitan area: a case study for the Xuzhou metropolitan area," Chinese Geographical Science, vol. 30, pp. 352-365, 2020.

[64] B. Zhu, M. Zhang, Y. Zhou et al., "Exploring the effect of industrial structure adjustment on interprovincial green development efficiency in China: a novel integrated approach," Energy Policy, vol. 134, Article ID 110946, 2019.

[65] Y. Guo, L. Tong, and L. Mei, "The effect of industrial agglomeration on green development efficiency in northeast China since the revitalization," Journal of Cleaner Production, vol. 258, Article ID 120584, 2020.

[66] L. Ma, H. Long, K. Chen, S. Tu, Y. Zhang, and L. Liao, “Green growth efficiency of Chinese cities and its spatio-temporal pattern," Resources, Conservation and Recycling, vol. 146, pp. 441-451, 2019.

[67] C. Feng, M. Wang, G.-C. Liu, and J.-B. Huang, "Green development performance and its influencing factors: a global perspective," Journal of Cleaner Production, vol. 144, pp. 323-333, 2017.

[68] W. Pan, W. Pan, C. Hu et al., "Assessing the green economy in China: an improved framework," Journal of Cleaner Production, vol. 209, pp. 680-691, 2019.

[69] L. Chen, X. Zhang, F. He, and R. Yuan, "Regional green development level and its spatial relationship under the constraints of haze in China," Journal of Cleaner Production, vol. 210, pp. 376-387, 2019.

[70] S. Shao, R. Luan, Z. Yang, and C. Li, "Does directed technological change get greener: empirical evidence from Shanghai's industrial green development transformation," Ecological Indicators, vol. 69, pp. 758-770, 2016.

[71] W. Sun and Q. Gao, "Exploration of energy saving potential in China power industry based on Adaboost back propagation neural network," Journal of Cleaner Production, vol. 217, pp. 257-266, 2019.
[72] X. Li, P. S. W. Fong, S. Dai, and Y. Li, “Towards sustainable smart cities: an empirical comparative assessment and development pattern optimization in China," Journal of Cleaner Production, vol. 215, pp. 730-743, 2019.

[73] Z. Wu, R. Chen, M. E. Meadows, D. Sengupta, and D. Xu, "Changing urban green spaces in Shanghai: trends, drivers and policy implications," Land Use Policy, vol. 87, Article ID 104080, 2019.

[74] Q. Ji, C. Li, and P. Jones, "New green theories of urban development in China," Sustainable Cities and Society, vol. 30, pp. 248-253, 2017.

[75] M. L. Derkzen, A. J. van Teeffelen, H. Nagendra, and P. H. Verburg, "Shifting roles of urban green space in the context of urban development and global change," Current Opinion in Environmental Sustainability, vol. 29, pp. 32-39, 2017.

[76] M. Contesse, B. J. M. van Vliet, and J. Lenhart, "Is urban agriculture urban green space? A comparison of policy arrangements for urban green space and urban agriculture in Santiago de Chile," Land Use Policy, vol. 71, pp. 566-577, 2018.

[77] K. Lv, X. Feng, S. Kelly, L. Zhu, and M. Deng, “A study on embodied carbon transfer at the provincial level of China from a social network perspective," Journal of Cleaner Production, vol. 225, pp. 1089-1104, 2019.

[78] K. Feng, K. Hubacek, L. Sun, and Z. Liu, "Consumption-based $\mathrm{CO}_{2}$ accounting of China's megacities: the case of Beijing, Tianjin, Shanghai and Chongqing," Ecological Indicators, vol. 47, pp. 26-31, 2014.

[79] W. Pan, W. Pan, Y. Shi et al., "China's inter-regional carbon emissions: an input-output analysis under considering national economic strategy," Journal of Cleaner Production, vol. 197, pp. 794-803, 2018.

[80] C. Cai and J. Shang, "Comprehensive evaluation on urban sustainable development of Harbin city in northeast China," Chinese Geographical Science, vol. 19, no. 2, pp. 144-150, 2009.

[81] S. Li and X. Luo, "Emergy assessment and sustainability of ecological-economic system using gis in China," Acta Ecologica Sinica, vol. 35, no. 5, pp. 160-167, 2015.

[82] C. Fang, X. Cui, G. Li et al., "Modeling regional sustainable development scenarios using the urbanization and eco-environment Coupler: case study of Beijing-Tianjin-Hebei urban agglomeration, China," Science of The Total Environment, vol. 689, pp. 820-830, 2019.

[83] C. V. Hawkins and X. Wang, "Sustainable development governance: citizen participation and support networks in local sustainability initiatives," Public Works Management \& Policy, vol. 17, no. 1, pp. 7-29, 2012.

[84] M.-X. Wang, H.-H. Zhao, J.-X. Cui et al., "Evaluating green development level of nine cities within the Pearl river delta, China," Journal of Cleaner Production, vol. 174, pp. 315-323, 2018. 